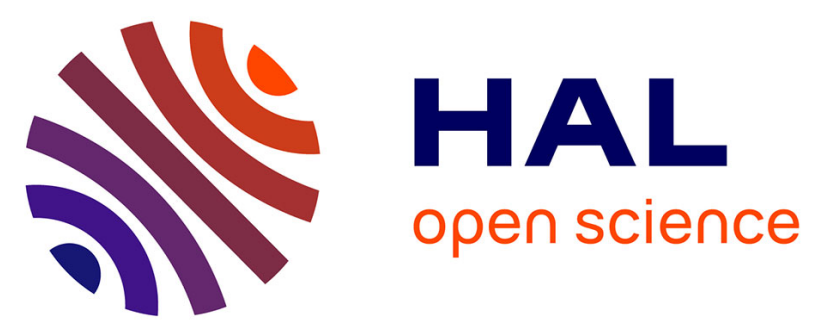

\title{
Sarcopenia in patients after an episode of acute decompensated heart failure: An underdiagnosed problem with serious impact
}

Romain Eschalier, Grégoire Massoullié, Yves Boirie, Marie Blanquet, Aurélien Mulliez, Pierre-Louis Tartière, Stefan Anker, Marie-Claire d'Agrosa Boiteux, Ruddy Richard, Frédéric Jean, et al.

\section{To cite this version:}

Romain Eschalier, Grégoire Massoullié, Yves Boirie, Marie Blanquet, Aurélien Mulliez, et al.. Sarcopenia in patients after an episode of acute decompensated heart failure: An underdiagnosed problem with serious impact. Clinical Nutrition, 2021, 40 (6), pp.4490-4499. 10.1016/j.clnu.2020.12.033 . hal-03516367

\section{HAL Id: hal-03516367 \\ https://hal.inrae.fr/hal-03516367}

Submitted on 17 Jan 2022

HAL is a multi-disciplinary open access archive for the deposit and dissemination of scientific research documents, whether they are published or not. The documents may come from teaching and research institutions in France or abroad, or from public or private research centers.
L'archive ouverte pluridisciplinaire HAL, est destinée au dépôt et à la diffusion de documents scientifiques de niveau recherche, publiés ou non, émanant des établissements d'enseignement et de recherche français ou étrangers, des laboratoires publics ou privés.

\section{(1) (1) $\$$}

Distributed under a Creative Commons Attribution - NonCommercial - NoDerivatives 44.0 
Original article

\title{
Sarcopenia in patients after an episode of acute decompensated heart failure: An underdiagnosed problem with serious impact
}

\author{
Romain Eschalier ${ }^{\mathrm{a}, \mathrm{k}, \text { * }}$, Grégoire Massoullié ${ }^{\mathrm{a}}$, Yves Boirie ${ }^{\mathrm{b}}$, Marie Blanquet ${ }^{\mathrm{c}}$, \\ Aurélien Mulliez ${ }^{\mathrm{d}}$, Pierre-Louis Tartière ${ }^{\mathrm{a}}$, Stefan Anker ${ }^{\mathrm{e}}$, Marie-Claire D'Agrosa Boiteux ${ }^{\mathrm{f}}$, \\ Ruddy Richard ${ }^{\mathrm{b}}$, Frédéric Jean ${ }^{\mathrm{a}}$, Nicolas Combaret ${ }^{\mathrm{a}}$, Géraud Souteyrand ${ }^{\mathrm{a}}$,

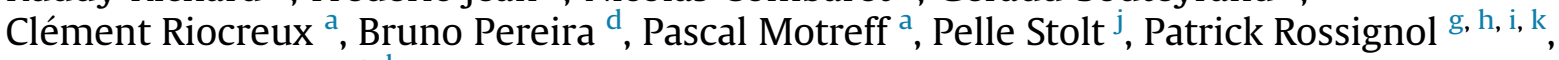 \\ Guillaume Clerfond ${ }^{\mathrm{a}, \mathrm{k}}$
}

\footnotetext{
a Cardiology Department, CHU Clermont-Ferrand, Clermont-Ferrand, France and Université Clermont Auvergne, CHU Clermont-Ferrand, CNRS, SIGMA Clermont, Institut Pascal, F-63000, Clermont-Ferrand, France

${ }^{\mathrm{b}}$ Clinical Nutrition Department, CHU Clermont-Ferrand, Université Clermont Auvergne, Unité de Nutrition Humaine, INRA, CRNH Auvergne, F-63000, Clermont-Ferrand, France

${ }^{\mathrm{c}}$ Medecine Department, CH Mauriac and Public Health Department Service de Santé Publique, CHU Clermont-Ferrand, Clermont-Ferrand, France and

Université Clermont Auvergne, CHU Clermont-Ferrand, CNRS, SIGMA Clermont, Institut Pascal, F-63000, Clermont-Ferrand, France

d Biostatistics Unit (Clinical Research and Innovation Direction), CHU Clermont-Ferrand, Clermont-Ferrand, France

e Department of Cardiology (CVK), Berlin Institute of Health Center for Regenerative Therapies (BCRT), German Centre for Cardiovascular Research (DZHK)

Partner Site Berlin, Charité Universitätsmedizin Berlin, Germany

f Durtol Cardiac Rehabilitation Center, Durtol, France

Lorraine Université, France

h INSERM, Centre d'Investigation Clinique CIC-P 1433, CHRU Nancy, Nancy, F-54000, France

i INSERM U1116, Nancy, France

${ }^{\mathrm{j}}$ MagliaRotta, Basel, Switzerland

${ }^{\mathrm{k}}$ F-CRIN, INI-CRCT, Nancy, France
}

\section{A R T I C L E I N F O}

\section{Article history:}

Received 17 August 2020

Accepted 26 December 2020

\section{Keywords:}

Chronic heart failure

Sarcopenia

Dysmobility

Decompensation

\begin{abstract}
S U M M A R Y
Background \& aims: Sarcopenia is a multifactorial syndrome resulting in a decrease in both muscle mass and function. Little is known about the prevalence and prognostic impact of sarcopenia in patients with acutely decompensated chronic heart failure (ADHF). We aimed to evaluate the prevalence (main endpoint) and impact of sarcopenia on ADHF patients.

Methods: 140 ADHF patients were enrolled between November 2014 and September 2018 in a multicenter prospective longitudinal study. A similar, independent multi-departmental cross-sectional study in 165 ADHF patients was used for external validation of prevalence data. All subjects were assessed on the European Working Group on Sarcopenia criteria.

Results: Ninety-one patients (65\%) had sarcopenia (vs. 53.6\% in the external replication regional cohort). Patients with sarcopenia were older and more likely to have eGFR $<60 \mathrm{ml} / \mathrm{min} / 1.73 \mathrm{~m}^{2}$ ( $\mathrm{p}<0.001$ and $\mathrm{p}=0.002$ ). Sarcopenia was associated with impaired functional status [lower 6 min walking test $(220 \pm 108$ vs. $279 \pm 170, \mathrm{p}=0.03)$ and $4 \mathrm{~m}$ gait speed $(0.56 \pm 0.24$ vs. $0.80 \pm 0.37, \mathrm{p}<0.001)]$ and autonomy [Instrumental activities of daily living: $6.7 \pm 1.4$ vs. $7.3 \pm 1.2, \mathrm{p}=0.005$ ]. Over up to 4 years' follow-up, 30 cardiovascular (CV) deaths and 42 non-CV deaths occurred. In a multivariable analysis, sarcopenia was associated with time to first non-CV hospitalization (hazard ratio 1.93; 95\% confidence interval $1.14-3.24 ; \mathrm{p}=0.014$ ) but not with any other hospitalization, any mortality endpoint, or a composite endpoint of $\mathrm{CV}$ death and $\mathrm{HF}$ hospitalization.

Conclusions: The prevalence of sarcopenia in ADHF patients is high and associated with greater risk of non-CV hospitalizations, highlighting the importance of identifying and managing the condition in a multidisciplinary approach.

Clinical trial registration: NCT03153774
\end{abstract}

(c) 2021 Elsevier Ltd and European Society for Clinical Nutrition and Metabolism. All rights reserved.

\footnotetext{
* Corresponding author. Cardiology Department, Rue Montalembert, 63000, Clermont-Ferrand, France. Fax: +33473754730

E-mail address: reschalier@chu-clermontferrand.fr (R. Eschalier).
} 


\section{Introduction}

Sarcopenia was recently recognized as a disease with the ICD10 code M62.84, confirming the importance of the condition as well as the high quality of sarcopenia research in the last decade. The estimated prevalence is between 5 and 13\% among adults aged over 60 years, rising to more than $50 \%$ in those aged 80 and above [1]. The term secondary sarcopenia is used today in the context of muscle atrophy associated with chronic diseases. Sarcopenia is associated with increased mortality and disability, independently of other factors [2] and compounds the already severe prognosis of chronic diseases such as chronic heart failure (HF) [3]. However, the identification and management of sarcopenia by clinicians remain challenging, in part because as a universal definition is lacking [4].

Like sarcopenia, HF is primarily a disease of aging: the prevalence increases sharply with age reaching up to $10 \%$ after age 70 [5]. Patients with HF have a propensity to develop muscle atrophy associated with metabolic disorders [6]. The peripheral hypothesis states that, while cardiac dysfunction is the primary driver of chronic HF, other organs and systems play a role in the progression of disease, and increases the severity of symptoms, with particular relevance to the renal, endocrine and immune systems, but also striated skeletal muscle [7]. The Studies Investigating Comorbidities Aggravating Heart Failure (SICA-HF) survey indicated that around $20 \%$ of stable patients with HF may have sarcopenia (only diagnosed by muscle wasting), with no difference between $\mathrm{HF}$ with preserved ejection fraction (HFpEF) and HF with reduced ejection fraction (HFrEF) [8,9]. However, little is known about the prevalence and impact of sarcopenia (muscle mass and impairment in muscle function or strength) on patients hospitalized with acutely decompensated HF (ADHF).

The main aim of the present study was to assess the prevalence of sarcopenia immediately following an episode of decompensation. A secondary aim was to assess the impact of sarcopenia on clinical outcomes after acutely decompensated HF (ADHF).

\section{Materials and methods}

\subsection{Study population}

The study cohort consisted of 140 patients, prospectively included between November 2014 and September 2018 at Clermont-Ferrand University Hospital or the Durtol Cardiac Rehabilitation Center. Enrolment criteria were adult age, HF (history of previous hospitalization for HF with the diagnosis of $\mathrm{HF}$ according to the 2012 European guidelines) and hospitalization for acute decompensation. Patients with acute malignancy, who were not covered by social security and unable to understand the written information provided about the study were excluded. Patients unable to complete the 4-m gait speed (4MGS) test and the palmar grip strength test (i.e. bedridden patients and patients unable to remain upright more than few seconds) were also not included.

The study complied with the Declaration of Helsinki. The locally appointed ethics committee [Comité de Protection des Personnes Sud-Est VI (AU1132)] and the national French Agency ANSM (2014A00938-39) approved the research protocol. Informed consent was obtained from all subjects. The study is registered on Clinicaltrials.gov under NCT03153774.

For each included patient, the following general assessments were performed: clinical examination, standard 12-lead electrocardiogram, standardized transthoracic echocardiogram and geriatric evaluation (activities of daily living [ADL] and Instrumental
Activities of Daily Living [IADL]), functional evaluation including Short Physical Performance Battery (SPPB) test and the 6-min walk test. Biological blood tests included blood count, C-Reactive Protein (CRP), liver assessments (ASAT, ALT, total bilirubin), LDH, CPK, serum sodium, serum potassium, blood urea nitrogen, creatinine, total protein, albumin, pre-albumin, orosomucoid and NT-ProBNP at admission prior to diuretic therapy.

For additional validation of the prevalence data we used data from a similar multi-departmental cross-sectional study (French ethical research committee AU 1289) in ADHF patients conducted between September 2017 and June 2018 in two general hospitals in the same administrative region as the main study. One center was a multidisciplinary general-medicine unit and the other a a geriatric unit. Inpatients aged $\geq 75$ years old were included. Sarcopenia was identified using EWGSOP 1, bioimpedance analysis (BIA) and the same criteria for muscle mass and function as the main study. The Modified Cumulative Illness Rating Scale-Geriatrics (CIRS-G) was used to measure comorbidity. No follow-up or cardiac assessment was performed.

\subsection{Sarcopenia: definition and diagnostic criteria}

We applied the diagnostic algorithm proposed by the European Working Group on Sarcopenia (EWGSOP) [10], which is based on the combination of a decrease in muscle mass and impairment in muscle function or strength. The quantification of muscle mass was performed via BIA measurement performed between the wrist and the right ankle in subjects in supine position using a Bodystat ${ }^{\circledR}$ QuadScan 4000 model impedance meter. Muscle mass was calculated from the BIA data according to the equation by Janssen [11] and indexed to body surface. Since BIA data can be influenced by the patient's hydration status, only clinically euvolemic patients were included, after complete regression of HF signs either at the end of hospitalization, after discontinuing intravenous diuretics, or at the beginning of their rehabilitation stay. BIA measurements were also performed in patients with electronic implantable cardiac devices [12]. The threshold for reduced muscle mass index (MMI) was $10.75 \mathrm{~kg} / \mathrm{m}^{2}$ for men and $6.75 \mathrm{~kg} / \mathrm{m}^{2}$ for women, corresponding to one standard deviation reduction from the mean obtained for a published reference population [11] and validated by the EWGSOP [10].

Physical performance was quantified by the $4 \mathrm{MGS}$ test. The threshold value for the diagnosis of sarcopenia was $0.8 \mathrm{~m} / \mathrm{s}$. Quantification of muscle strength was performed by the palmar grip strength test using a Lafayette Hand Dynamometer (Lafayette Instrument ${ }^{\circledR}$ ) - type hand grip. Two successive measurements were performed with the strongest hand and the highest measurement was used. The threshold values for the diagnosis of sarcopenia were $30 \mathrm{~kg}$ for men and $20 \mathrm{~kg}$ for women.

\subsection{Clinical outcomes assessments}

Clinical outcomes (death and hospitalization) were reported by medical consultation report or hospitalization in both centers, or by telephone (cardiologist, general practitioner) and recorded, including date and place, in the electronic case report form. Maximum follow-up was 48 months. For hospitalizations, the letter of discharge was to be provided, while the death certificate was to be provided to confirm deaths. Two blinded investigators, not involved in the design or conduct of the study, adjudicated events. The diagnosis of sarcopenia was only ascertained at the end of the inclusion and follow-up period. 


\subsection{Statistical analyses}

The sample size calculation was based on the estimated prevalence of sarcopenia immediately following an episode of decompensation, with a reasonable and relevant precision of the $95 \%$ confidence interval. However, data reported in the litterature concerning the prevalence of sarcopenia are heterogeneous. For an expected prevalence at $50 \%$, it was estimated that 140 patients were needed in order to achieve an accuracy $\pm 8 \%$.

Categorical variables are presented as numbers and percentages; continuous variables are given as mean and standarddeviations, or median and interquartile range [IQR] and range (minimum - maximum). Normality was assessed graphically and using the Shapiro-Wilk's test. The comparisons between sarcopenic vs. non sarcopenic patients were carried out using the Chisquare test, or Fisher's exact test when appropriate, for categorical data, and with the Student's t-test or the Mann-Whitney's test when the assumptions for t-test were not met, for continuous data. Results are presented as Hedge's effect-size and 95\% confidence interval [95\% IC], and as forest-plots as appropriate.

Censored data (death, hospitalization) were analyzed for time from initial inclusion/HF decompensation to first event, and time from initial inclusion/HF decompensation to event allowing for multiple events (taking a patient as cluster to account for the dependence of recurrent events) using Kaplan-Meier survival curves. The comparisons were performed using the log-rank test and marginal Cox model for repeated measures. Multivariable analysis was performed using the Cox proportional-hazards model. Variables were selected according to clinical relevance and to univariate analyses. A stepwise (backward and forward) selection method was used with a removal probability $>0.15$ and an entry probability $<0.05$. This procedure was followed by a hand step by step procedure supervised by the clinician in order to adjust for clinically relevant covariates that had been discarded in the selection. A particular attention was paid to possible multicollinearity.

The results are presented with hazard-ratios (HR) and 95\% confidence intervals. The proportional-hazard hypothesis was studied using Schoenfeld's test and plotting residuals. A sensitivity analysis was carried out to characterize the statistical nature of missing data. As $<5 \%$ of data were missing for parameters reported for main analyses, handling of missing data was not applied. A twosided $\mathrm{p}$ value of $<0.05$ was used for statistical significance. As univariate analyses could be considered exploratory and principally helpful to determine covariates candidate to multivariable, we have chosen (i) to report all the individual p-values and confidence intervals, without doing any mathematical correction for distinct tests comparing two modalities [13,14] and (ii) paid specific attention to the magnitude of differences and to clinical relevance (Hedge's effect size for sarcopenia vs no sarcopenia comparisons and hazard ratio for survival models). All statistical analyses were carried out using Stata (version 12, StataCorp, College Station, US).

\section{Results}

\subsection{Study population}

A total of 91 of 140 included patients were identified as sarcopenic, a prevalence rate of $65 \%$ [57.1\%-72.9\%] (Fig. 1). Five patients were excluded from the analysis since they could not perform the 4MGS test and the palmar grip strength test.

The independent cross-sectional study used for validation purposes included 223 patients [104 women (63\%) and 61 men (37\%)], with a mean age $86.2 \pm 4.8$ years. In this study, 165 patients were diagnosed with HF. A diagnostic workup for sarcopenia was performed in 140 patients. The prevalence of sarcopenia was $53.6 \%$ (95\% Cl 45.3\%-61.8\%).

The characteristics of the present study population including a comparison between sarcopenic and non-sarcopenic patients are presented in Table 1.

Mean age was significantly higher in the sarcopenic group $(78.2 \pm 9.0$ vs. $71.4 \pm 10.9$ years, $\mathrm{p}<0.001)$. Sarcopenic patients had significantly lower BMI $\left(25.9 \pm 5.3 \mathrm{vs} .28 .5 \pm 5.6 \mathrm{~kg} / \mathrm{m}^{2}, \mathrm{p}=0.006\right)$, but the proportion of obese patients was similar in both groups. The sex ratio was similar in both groups $(\mathrm{p}=0.801)$. Twelve out of 140 (8.6\%) patients with no difference between the groups (4/49 (8.2\%) in the non-sarcopenic group vs. $8 / 91$ (8.8\%) in the sarcopenic group, $\mathrm{p}=1$ ) presented inflammatory risk factors or comorbidities: bullous pemphigoid, osteitis, urothelial neoplasia, myeloma, Gougerot Sjögren Syndrome, Lupus, chronic lymphocytic leukemia, rheumatoid arthritis, myelodysplasia and prostate neoplasia.

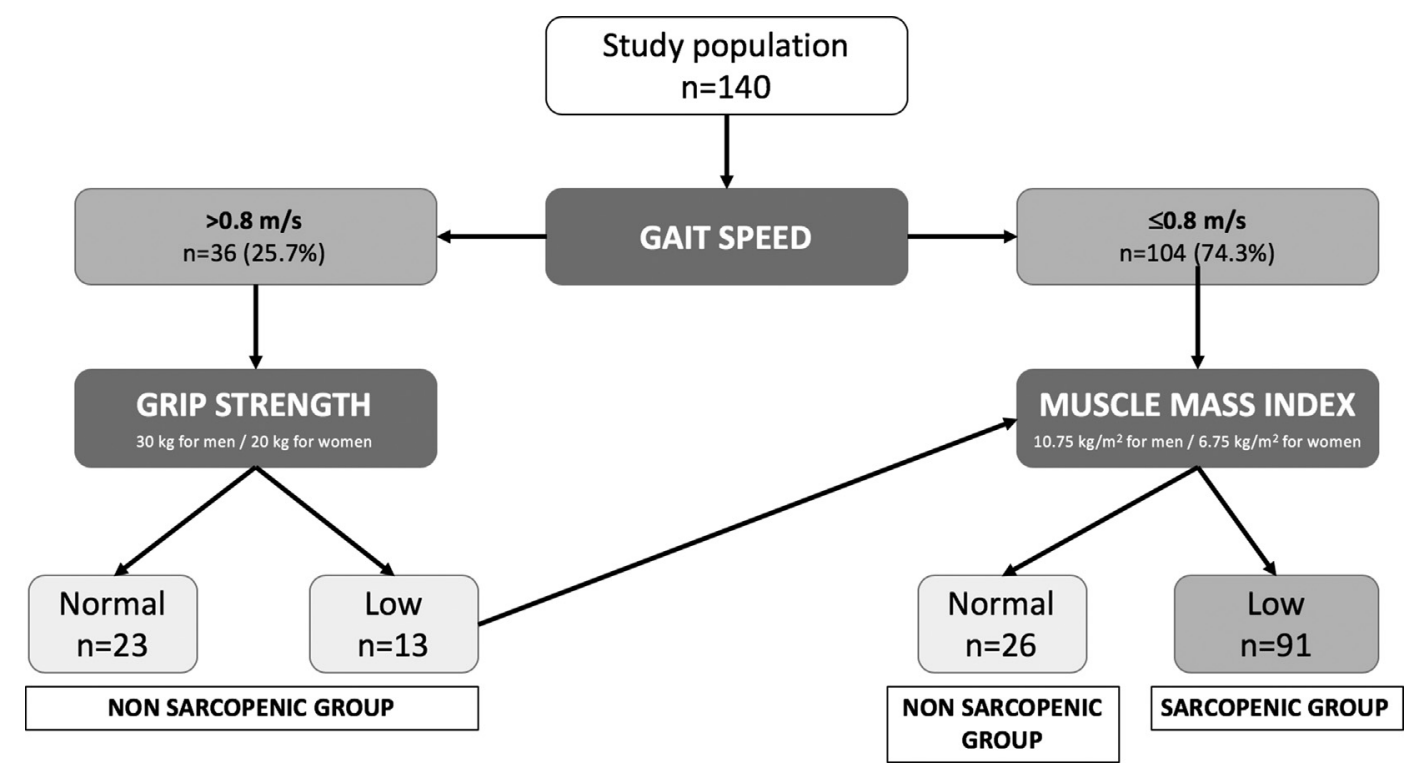

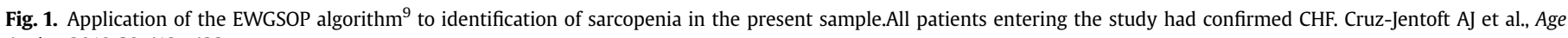
Ageing 2010;39:412-423. 
Table 1

Clinical features of CHF patients included in the study.

\begin{tabular}{|c|c|c|c|c|}
\hline & $\begin{array}{l}\text { Total } \\
\mathrm{N}=140\end{array}$ & $\begin{array}{l}\text { Sarcopenic } \\
\mathrm{N}=91\end{array}$ & $\begin{array}{l}\text { Non-sarcopenic } \\
\mathrm{N}=49\end{array}$ & p-value \\
\hline \multicolumn{5}{|l|}{ Clinical characteristics } \\
\hline Mean age $\pm \mathrm{SD}(\max -\min )$ & $75.8 \pm 10.2(48-94)$ & $78.2 \pm 9.0(53-94)$ & $71.4 \pm 10.9(48-92)$ & $<0.001$ \\
\hline Age $>85$ years & $23(16.4 \%)$ & $19(20.9 \%)$ & $4(8.2 \%)$ & 0.053 \\
\hline Sex ratio & 1.41 & 1.46 & 1.33 & 0.801 \\
\hline Men/Women & $82 / 58$ & $54 / 37$ & $28 / 21$ & \\
\hline $\mathrm{BMI} \mathrm{kg} / \mathrm{m}^{2}$ & $26.8 \pm 5.5$ & $25.9 \pm 5.3$ & $28.5 \pm 5.6$ & 0.006 \\
\hline $\mathrm{BMI}>30 \mathrm{~kg} / \mathrm{m}^{2}$ & $38(27.1 \%)$ & $21(23.1 \%)$ & $17(34.7 \%)$ & 0.140 \\
\hline NYHA stage & & & & 0.059 \\
\hline 1 & $30(21.4 \%)$ & $15(16.5 \%)$ & $15(30.6 \%)$ & \\
\hline 2 & $73(52.1 \%)$ & $49(53.8 \%)$ & $24(49.0 \%)$ & \\
\hline 3 & $33(23.6 \%)$ & $24(26.4 \%)$ & $9(18.4 \%)$ & \\
\hline 4 & $4(2.9 \%)$ & $3(3.3 \%)$ & $1(2.0 \%)$ & \\
\hline Recent loss of weight & $19(13.6 \%)$ & $13(14.3 \%)$ & $6(12.2 \%)$ & 0.737 \\
\hline \multicolumn{5}{|l|}{ CV risk factors } \\
\hline Hypertension & $86(61.4 \%)$ & $61(67.0 \%)$ & $25(51.0 \%)$ & 0.063 \\
\hline Dyslipidemia & $57(40.7 \%)$ & $38(41.8 \%)$ & $19(38.8 \%)$ & 0.732 \\
\hline Diabetes & $61(43.6 \%)$ & $41(45.1 \%)$ & $20(40.8 \%)$ & 0.630 \\
\hline Tobacco use & $53(37.9 \%)$ & $34(37.4 \%)$ & $19(38.8 \%)$ & 0.869 \\
\hline Active & $5(3.6 \%)$ & $4(4.4 \%)$ & $1(2.0 \%)$ & 0.657 \\
\hline Family history of CV disease & $18(12.9 \%)$ & $9(9.9 \%)$ & $9(18.4 \%)$ & 0.153 \\
\hline \multicolumn{5}{|l|}{ Comorbidities } \\
\hline \multicolumn{5}{|l|}{ Chronic Kidney Disease } \\
\hline$G F R<60 \mathrm{~mL} / \mathrm{min} / 1.73 \mathrm{~m}^{2}$ & $102(72.9 \%)$ & $72(79.1 \%)$ & $30(61.2 \%)$ & 0.002 \\
\hline$G F R<30 \mathrm{~mL} / \mathrm{min} / 1.73 \mathrm{~m}^{2}$ & $23(16.4 \%)$ & $14(15.4 \%)$ & $9(18.4 \%)$ & 0.65 \\
\hline COPD & $23(16.4 \%)$ & $18(19.8 \%)$ & $5(10.2 \%)$ & 0.145 \\
\hline Inflammatory disease & $12(8.6 \%)$ & $8(8.8 \%)$ & $4(8.2 \%)$ & 1 \\
\hline Vascular arteriopathy & $12(8.6 \%)$ & $8(8.8 \%)$ & $4(8.2 \%)$ & 1 \\
\hline \multicolumn{5}{|l|}{ Cardiac etiology } \\
\hline Ischemic & $52(37.1 \%)$ & $38(41.8 \%)$ & $14(28.6 \%)$ & 0.124 \\
\hline Hypertensive & $7(5.0 \%)$ & $2(2.2 \%)$ & $5(10.2 \%)$ & 0.051 \\
\hline Valvular & $19(13.6 \%)$ & $11(12.1 \%)$ & $8(16.3 \%)$ & 0.485 \\
\hline Rhythmic & $20(14.3 \%)$ & $16(17.6 \%)$ & $4(8.2 \%)$ & 0.129 \\
\hline DCM & $17(12.1 \%)$ & $12(13.2 \%)$ & $5(10.2 \%)$ & 0.606 \\
\hline Iatrogenic & $4(2.9 \%)$ & $1(1.1 \%)$ & $3(6.1 \%)$ & 0.123 \\
\hline Other & $21(15.0 \%)$ & $11(12.1 \%)$ & $10(20.4 \%)$ & 0.188 \\
\hline Duration of HF in months, median [IQR] & $72[24-120]$ & $84[36-132]$ & $48[18-108]$ & 0.056 \\
\hline (extremes) & $(4-420)$ & $(6-324)$ & $(4-420)$ & \\
\hline Valve prosthesis & $19(13.6 \%)$ & $13(14.3 \%)$ & $6(12.2 \%)$ & 0.737 \\
\hline Bypass surgery & $21(15 \%)$ & $15(16.5 \%)$ & $6(12.2 \%)$ & 0.503 \\
\hline SVT & $57(40.7 \%)$ & $42(46.2 \%)$ & $15(30.6 \%)$ & 0.074 \\
\hline $\operatorname{LVEF}(\%)$ & $42.0 \pm 14.4$ & $42.8 \pm 14.7$ & $40.7 \pm 14.0$ & 0.428 \\
\hline LVEF $<40 \%$ & $68(48.9 \%)$ & $42(46.7 \%)$ & $26(53.1 \%)$ & 0.739 \\
\hline $40<\mathrm{LVEF}<50 \%$ & $23(16.6 \%)$ & $15(16.7 \%)$ & $8(16.3 \%)$ & \\
\hline LVEF $>50 \%$ & $48(34.5 \%)$ & $33(36.7 \%)$ & $15(30.6 \%)$ & \\
\hline Precipitating factors for HF hospitalization & & & & 0.845 \\
\hline None identified/evolution of cardiopathy, $n$ (\%) & $68(48.9 \%)$ & $44(48.3 \%)$ & $24(50 \%)$ & $0.04[-0.35 ; 0.42]$ \\
\hline Anemia, $n(\%)$ & $7(5 \%)$ & $4(4.4 \%)$ & $3(6.3 \%)$ & $0.2[-0.64 ; 1.05]$ \\
\hline Atrial fibrillation, $n(\%)$ & $16(11.5 \%)$ & $12(13.2 \%)$ & $4(8.3 \%)$ & $\begin{array}{l}-0.28[-0.93 \\
0.37]\end{array}$ \\
\hline Pulmonary infection, $n$ (\%) & $9(6.5 \%)$ & $6(6.6 \%)$ & $3(6.3 \%)$ & $\begin{array}{l}-0.03[-0.82 \\
0.75]\end{array}$ \\
\hline Poor compliance (drugs or dietary), $n(\%)$ & $15(10.8 \%)$ & $9(9.9 \%)$ & $6(12.5 \%)$ & $0.14[-0.46 ; 0.75]$ \\
\hline Acute arterial hypertension, $n(\%)$ & $1(0.7 \%)$ & $1(1.1 \%)$ & $0(0 \%)$ & $\mathrm{NC}$ \\
\hline Acute kidney diseases, $n(\%)$ & $4(2.9 \%)$ & $3(3.3 \%)$ & $1(2.1 \%)$ & $-0.26[-1.51 ; 1]$ \\
\hline New ischemic events, $n(\%)$ & $4(2.9 \%)$ & $4(4.4 \%)$ & $0(0 \%)$ & $\mathrm{NC}$ \\
\hline Other, $n(\%)$ & $8(5.8 \%)$ & $5(5.5 \%)$ & $3(6.2 \%)$ & $0.08[-0.73 ; 0.88]$ \\
\hline Other infection, $n(\%)$ & $7(5 \%)$ & $3(3.3 \%)$ & $4(8.3 \%)$ & $0.54[-0.31 ; 1.38]$ \\
\hline \multicolumn{5}{|l|}{ Treatment } \\
\hline \multicolumn{5}{|l|}{ Drugs } \\
\hline $\mathrm{ACEi}$ & $64(48.1 \%)$ & $39(44.8 \%)$ & $25(54.3 \%)$ & 0.296 \\
\hline ARB & $20(14.9 \%)$ & $12(13.6 \%)$ & $8(17.4 \%)$ & 0.562 \\
\hline MRA & $52(38.8 \%)$ & $33(37.5 \%)$ & $19(41.3 \%)$ & 0.668 \\
\hline Beta-blockers & 97 (71.9\%) & $65(73.9 \%)$ & $32(68.1 \%)$ & 0.477 \\
\hline Loop diuretics & $129(96.3 \%)$ & $86(97.7 \%)$ & $43(93.5 \%)$ & 0.339 \\
\hline Oral anticoagulants & $95(70.9 \%)$ & $62(70.5 \%)$ & $33(71.7 \%)$ & 0.876 \\
\hline Amiodarone & $45(33.6 \%)$ & $27(30.7 \%)$ & $18(39.1 \%)$ & 0.325 \\
\hline ONS & $20(14.3 \%)$ & $13(14.3 \%)$ & $7(14.3 \%)$ & 1 \\
\hline \multicolumn{5}{|l|}{ Electrical devices } \\
\hline PM & 27 (19.3\%) & $20(22.0 \%)$ & $7(14.3 \%)$ & 0.271 \\
\hline ICD & $33(23.6 \%)$ & $18(19.8 \%)$ & $15(30.6 \%)$ & 0.150 \\
\hline CRT & $10(7.1 \%)$ & $5(5.5 \%)$ & $5(10.2 \%)$ & 0.320 \\
\hline \multicolumn{5}{|l|}{ Biological characteristics } \\
\hline Hemoglobin $(\mathrm{g} / \mathrm{dL})$ & $12.7 \pm 1.9$ & $12.6 \pm 2.0$ & $12.8 \pm 1.8$ & 0.413 \\
\hline
\end{tabular}




\begin{tabular}{|c|c|c|c|c|}
\hline & $\begin{array}{l}\text { Total } \\
\mathrm{N}=140\end{array}$ & $\begin{array}{l}\text { Sarcopenic } \\
\mathrm{N}=91\end{array}$ & $\begin{array}{l}\text { Non-sarcopenic } \\
\mathrm{N}=49\end{array}$ & p-value \\
\hline Total protein $(\mathrm{g} / \mathrm{L})$ & $71.4 \pm 8.6$ & $71.6 \pm 9.4$ & $71.1 \pm 6.8$ & 0.74 \\
\hline Albumin $(\mathrm{g} / \mathrm{L})$ & $36.1 \pm 4.9$ & $35.5 \pm 4.7$ & $37.1 \pm 5.1$ & 0.076 \\
\hline Prealbumin (g/L) & $0.24 \pm 0.07$ & $0.23 \pm 0.07$ & $0.24 \pm 0.08$ & 0.436 \\
\hline $\mathrm{CRP}(\mathrm{mg} / \mathrm{L})$ & $6.4[2.9-14.4]$ & $7.1[2.9-15.5]$ & $5.3[2.9-10.7]$ & 0.148 \\
\hline \multicolumn{5}{|l|}{ median [IQR] } \\
\hline (extremes) & $(2.8-106)$ & $(2.8-106)$ & $(2.8-78)$ & \\
\hline Orosomucoid $(\mathrm{g} / \mathrm{L})$ & $1.03 \pm 0.34$ & $1.09 \pm 0.36$ & $0.94 \pm 0.26$ & 0.015 \\
\hline PINI median [IQR] (extremes) & $0.75[0.27-1.95](0.11-45.24)$ & $0.83[0.35-2.51](0.13-45.24)$ & $0.50[0.21-1.49](0.11-37.30)$ & 0.041 \\
\hline Creatinine $(\mu \mathrm{mol} / \mathrm{L})$ & $128.5 \pm 53.0$ & $129.6 \pm 48.1$ & $126.3 \pm 61.7$ & 0.729 \\
\hline eGFR $(\mathrm{ml} / \mathrm{min} / 1.73 \mathrm{~m} 2)$ & $49.9 \pm 21.1$ & $48.0 \pm 19.7$ & $53.3 \pm 14.2$ & 0.17 \\
\hline \multirow{2}{*}{$\begin{array}{l}\text { NT-ProBNP at admission (ng/L) median [IQR] } \\
\quad \text { (extremes) }\end{array}$} & $4808[2016-8946](227$ & $5400[2109-9266](227$ & $3331[1415-7593](377$ & 0.244 \\
\hline & $-83479)$ & $-29593)$ & $-83479)$ & \\
\hline \multirow[t]{2}{*}{ NT-ProBNP (ng/L) at discharge median [IQR] } & $5680[1204-5745](107$ & $2822[1383-5962](142$ & 2352 [876-5520] (107 & 0.245 \\
\hline & $-89552)$ & $-26286)$ & $-89552)$ & \\
\hline Vitamin $\mathrm{D}(\mu \mathrm{g} / \mathrm{L})$ & $17.9 \pm 10.8$ & $17.7 \pm 11.4$ & $18.4 \pm 9.7$ & 0.749 \\
\hline \multicolumn{5}{|l|}{ Functional characteristics } \\
\hline MMI $\left(\mathrm{kg} / \mathrm{m}^{2}\right)$ & $8.34 \pm 2.19$ & $7.67 \pm 1.82$ & $9.60 \pm 2.28$ & $<0.001$ \\
\hline Hand grip test $(\mathrm{kg})$ & $24.2 \pm 10.5$ & $22.4 \pm 8.8$ & $27.4 \pm 12.7$ & 0.007 \\
\hline SPPB & $6.2 \pm 2.7$ & $5.6 \pm 2.4$ & $7.2 \pm 2.9$ & 0.001 \\
\hline $4 \operatorname{MGS}(\mathrm{m} / \mathrm{s})$ & $0.65 \pm 0.31$ & $0.56 \pm 0.24$ & $0.80 \pm 0.37$ & $<0.001$ \\
\hline $6 \mathrm{MWT}(\mathrm{m})$ & $240 \pm 135$ & $220 \pm 108$ & $279 \pm 170$ & 0.03 \\
\hline ADL & $5.6 \pm 0.7$ & $5.6 \pm 0.6$ & $5.7 \pm 0.7$ & 0.307 \\
\hline IADL & $6.9 \pm 1.4$ & $6.7 \pm 1.4$ & $7.3 \pm 1.2$ & 0.005 \\
\hline
\end{tabular}

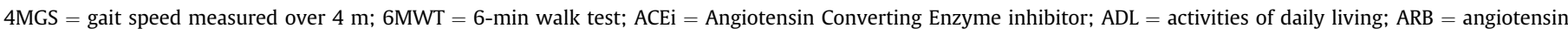

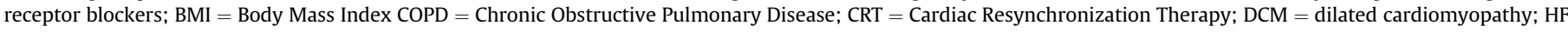

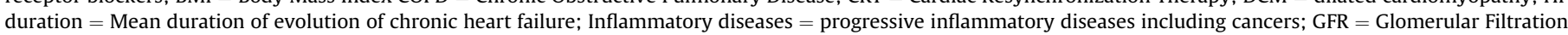

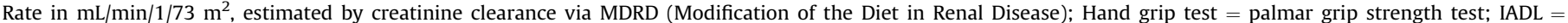

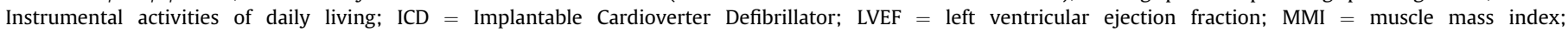

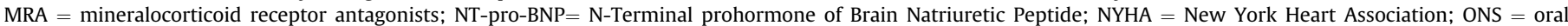

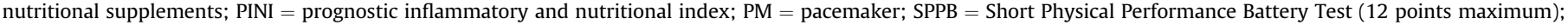
SVT $=$ Supraventricular tachycardia; $\mathrm{CI}=$ Confidence Interval.

Qualitative values are presented as absolute values and percentages. Quantitative values are presented as means \pm standard deviation and extreme values.

The time in hospital from admission to the time point of BIA assessment was 8 [5-14] days, with no difference between sarcopenic and non-sarcopenic groups (8 [5-13] vs. 8.5 [5-14] days, $\mathrm{p}=0.638$ ).

The median time from HF diagnosis was 72 months [IQR 24; 120], with non-significant longer duration in the non-sarcopenic group (48 [18; 108] vs. $84[36 ; 132]$ months, $\mathrm{p}=0.056)$. The severity of HF was comparable between the groups, with a nonsignificantly ( $\mathrm{p}=0.059$ ) higher percentage of sarcopenic patients in higher NYHA classes. The etiology of HF was similar in both groups. There were significantly more patients with eGFR $<60 \mathrm{ml} /$ $\min / 1.73 \mathrm{~m}^{2}$ in the sarcopenic group (79.1\% vs. $\left.61.2 \%, \mathrm{p}=0.002\right)$. Albumin and prealbumin levels were not significantly different in the two groups $(35.5 \pm 4.7 \mathrm{~g} / \mathrm{l}$ vs. $37.1 \pm 5.1 \mathrm{~g} / \mathrm{l}, \mathrm{p}=0.076)$. No difference was observed for precipitating factors according to age ( $<70$ vs. $\geq 70$ yrs; $\mathrm{p}=0.208$ ). More common factors in elderly were evolution of the cardiopathy (46.5\%), atrial fibrillation (13.9\%) and poor compliance (with diet or drugs, $11.9 \%$ ).

Pharmacological and device-based management of HF was similar in the two groups. The proportion of patients treated with oral nutritional supplements in the three months prior to inclusion was $14.3 \%$ in both groups.

There was no significant difference in CRP $(p=0.148)$, whereas orosomucoid, a marker of chronic inflammation, was significantly higher in sarcopenic patients $(1.09 \pm 0.36$ vs. $0.94 \pm 0.26 \mathrm{~g} / \mathrm{l}$, $\mathrm{p}=0.015)$. The Prognostic Inflammatory and Nutritional Index (PINI) score was significantly higher in sarcopenic patients $(0.83$ $[0.35 ; 2.51]$ vs. $0.50[0.21 ; 1.49] \mathrm{g} / \mathrm{l}, \mathrm{p}=0.041)$.

\subsection{Functional characteristics (Table 1)}

MMI $\left(7.67 \pm 1.82 \mathrm{~kg} / \mathrm{m}^{2}\right.$ vs. $\left.9.60 \pm 2.28 \mathrm{~kg} / \mathrm{m}^{2}, \mathrm{p}<0.001\right)$, gait speed $(0.56 \pm 0.24 \mathrm{~m} / \mathrm{s}$ vs. $0.80 \pm 0.37 \mathrm{~m} / \mathrm{s}, \mathrm{p}<0.001)$, and handgrip strength $(22.4 \pm 8.8$ vs. $27.4 \pm 12.7 \mathrm{~kg}, \mathrm{p}=0.007)$ were lower in the sarcopenic group, as were the SPPB test results $(5.6 \pm 2.4$ vs. $7.2 \pm 2.9, \mathrm{p}=0.001)$. Sarcopenic patients scored clinically worse on the 6-min walk test (6MWT) (207 [137-300] vs. 288 [124-368], $\mathrm{p}=0.127$ ). Autonomy assessed by the IADL score was also more impaired in sarcopenic patients: mean scores were $6.7 \pm 1.4$ vs. $7.3 \pm 1.2 ; \mathrm{p}=0.005$.

\subsection{Follow-up}

During a maximum of 4 years' follow-up median: 24 months [0-48], there were 72 deaths, $41.7 \%$ cardiovascular (CV) and $58.3 \%$ non-CV. The causes of non-CV death were mostly gastro-intestinal bleeding (14.6\%), cerebral bleeding (9.8\%), infection (14.6\%), neoplasia (14.6\%), acute renal injury (14.6\%), acute dyspnea patients with chronic obstructive pulmonary disease (4.9\%), and chronic kidney disease (4.9\%).

The risk for non-CV hospitalization in the time-to-first-event analysis was greater in patients with sarcopenia $(\mathrm{HR}=1.89$ [1.14-3.15], $\mathrm{p}=0.005)$. The increased risk did not reach statistical significance for HF hospitalization (HR 1.46 [0.89-2.4], $\mathrm{p}=0.091$ ) or the composite of CV death and HF hospitalization (HR 1.49 [0.92-2.42], $\mathrm{p}=0.064$ ). All-cause death (HR 1.35 [0.82-2.24], $\mathrm{p}=0.191$ ), CV death (HR 1.54 [0.68-3.46], $\mathrm{p}=0.272$ ) or CV hospitalization (HR 0.66 [0.37-1.16], $\mathrm{p}=0.123$ ) did not differ between patients with or without sarcopenia (Fig. 2).

In the multivariable analysis (Table 2), sarcopenia was associated with non-CV hospitalization in the time-to-first-event analysis, (HR 1.93 [1.14-3.24], p = 0.014), but not with any other hospitalization, any mortality endpoint, or the composite endpoint CV death and HF hospitalization (Fig. 3).

In the recurrent-event analysis patients with sarcopenia also showed a greater risk of non-CV hospitalization $(\mathrm{HR}=1.56$ 


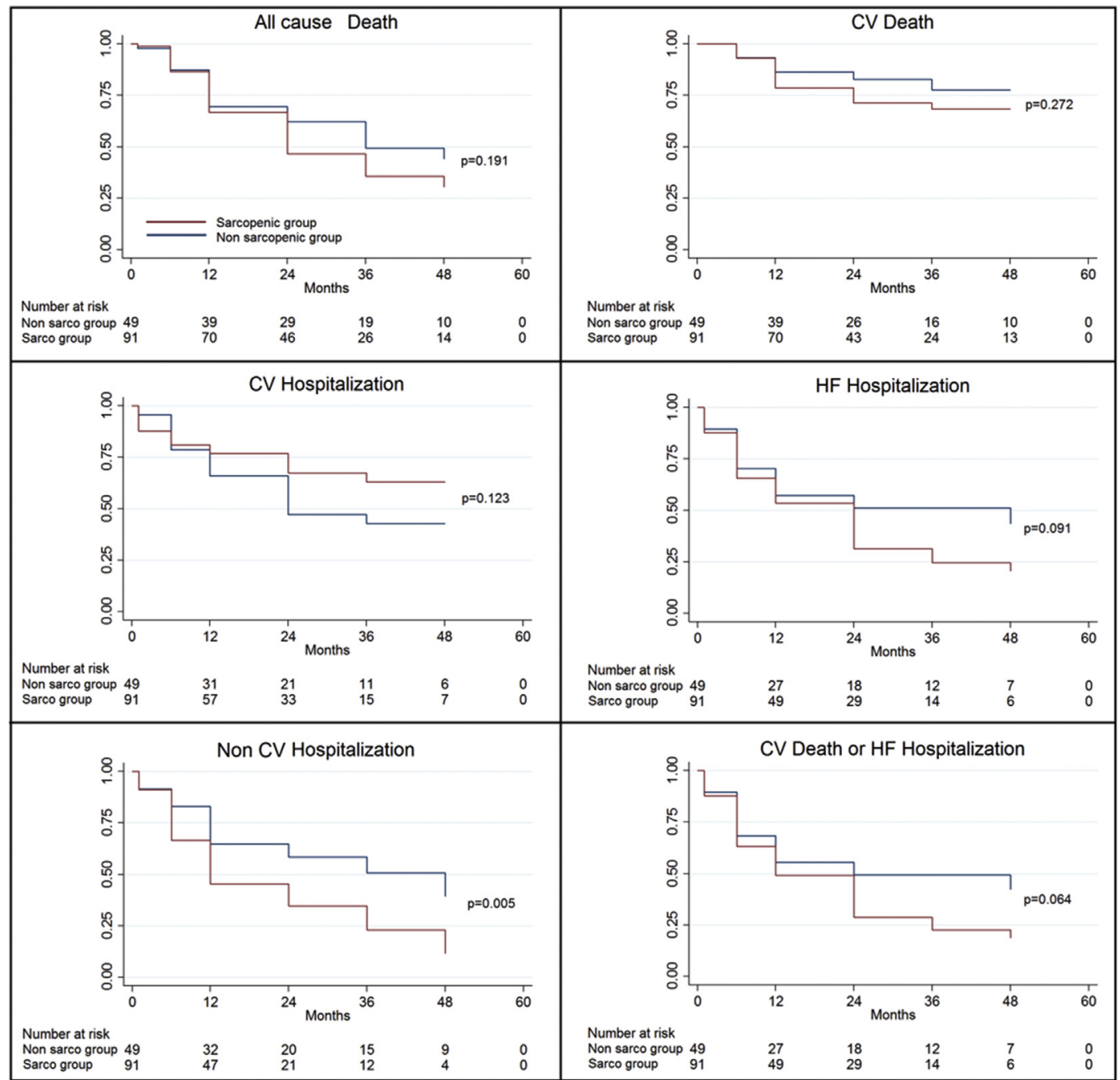

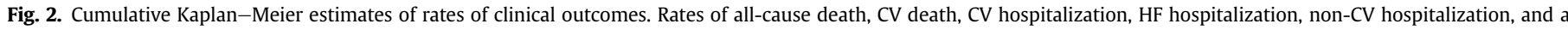

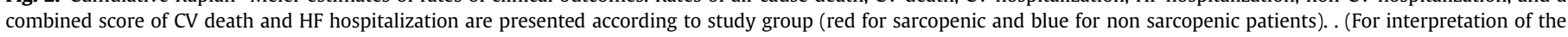
references to color in this figure legend, the reader is referred to the Web version of this article.)

[1.06-2.30], $\mathrm{p}=0.008$ ) and a trend toward an increased composite score CV death and HF hospitalization (HR 1.34 [0.91-1.99], $\mathrm{p}=0.085$ ) or all-cause hospitalization (HR 1.23 [0.95-1.58], $\mathrm{p}=0.051$ ) (Supplemental Fig. 2B).

In the multivariable analysis, sarcopenia was not associated with non-CV hospitalization (1.27 [0.86-1.88], $\mathrm{p}=0.23$ ), HF hospitalization ( $p=0.236$ ) or all-cause hospitalization $(p=0.253)$, while there was a trend toward increased CV hospitalization $(\mathrm{p}=0.08)$, in the recurrent-event analysis (Supplemental Fig. 3B).

\section{Discussion}

The prevalence of sarcopenia in a mixed cohort of patients with clinically relevant HF has been reported to be as high as $20 \%$ [17]. Our study is, to our knowledge, the first to assess the prevalence of sarcopenia specifically in ADHF patients and its impact on functional variables and mortality/morbidity endpoints in the medium term. In this very sick population the incidence of sarcopenia was very high (65\%). Although high, this is unlikely to be an outlier, as the prevalence was similar (53.6\%) in the cross-sectional ADHF study cohort used for validation. Etiology, LVEF status, or time from HF diagnosis did not appear to influence the prevalence of sarcopenia. In the multivariate analysis sarcopenia was associated with an almost doubling of the risk of non-CV hospitalizations over 4 years (trends for HF hospitalization, CV death and HF hospitalization), although there was no significant association with risk of mortality or other hospitalization endpoints.

A number of mechanisms may contribute to the high rates of sarcopenia in HF. HF is associated with wasting of myofibrillar proteins, of the diaphragm and quadriceps muscles [18]. Adverse effects of increased catabolic stress in the skeletal muscle of HF patients include insulin resistance, exercise intolerance, ventilatory inefficiency, and chronotropic incompetence. All these have a negative impact on functional status [19]. HF patients are also frequently malnourished to varying extent, possibly due to elevated levels of inflammatory cytokines. Malnutrition is especially relevant in patients hospitalized for acute HF in whom it is an independent predictor of long-term mortality [20]. In addition, the progressive reduction in physical activity and associated sedentariness of patients with HF will compound the metabolic effects.

Our population, although recruited in only two centers, appears broadly representative of patients hospitalized for HF. The characteristics are comparable to the French OFICA registry of 1658 patients hospitalized for $\mathrm{HF}$, including $72.2 \%$ with decompensated $\mathrm{HF}$ [21]. Furthermore, the use of drugs in patients with HFrEF were similar to what has been previously found in the French national 
Table 2A

Multivariate analysis of sarcopenia and different endpoints (time to first event).

\begin{tabular}{|c|c|c|c|c|}
\hline Endpoint & Variable & HR & {$[95 \% \mathrm{CI}]$} & p-value \\
\hline \multicolumn{5}{|c|}{ Non-cardiovascular Hospitalization } \\
\hline & Sarcopenia & 1.93 & {$[1.14-3.24]$} & 0.014 \\
\hline & CKD $\left(\mathrm{MDRD}<30 \mathrm{ml} / \mathrm{min} / \mathrm{m}^{2}\right)$ & 1.58 & {$[0.87-2.88]$} & 0.135 \\
\hline & Vascular arteriopathy & 2.46 & {$[1.05-5.80]$} & 0.039 \\
\hline & Dilated cardiomyopathy & 0.3 & {$[0.11-0.82]$} & 0.019 \\
\hline & Log NT-ProBNP & 1.03 & {$[0.84-1.27]$} & 0.746 \\
\hline \multicolumn{5}{|c|}{ All cause death } \\
\hline & Sarcopenia & 1 & {$[0.56-1.76]$} & 0.989 \\
\hline & ACEi & 0.57 & {$[0.34-0.95]$} & 0.032 \\
\hline & Log NT-ProBNP & 1.67 & {$[1.28-2.18]$} & $<\mathbf{0 . 0 0 1}$ \\
\hline & Orosomucoid & 2.38 & {$[1.12-5.08]$} & 0.024 \\
\hline & $\mathrm{BMI}>30 \mathrm{~kg} / \mathrm{m}^{2}$ & 0.97 & {$[0.48-1.95]$} & 0.934 \\
\hline & Age $>85$ years & 1.37 & {$[0.71-2.65]$} & 0.343 \\
\hline & LVEF & 0.99 & {$[0.97-1.01]$} & 0.545 \\
\hline \multicolumn{5}{|l|}{ CV death } \\
\hline & Sarcopenia & 1.06 & {$[0.45-2.47]$} & 0.896 \\
\hline & LVEF & 0.98 & {$[0.95-1.01]$} & 0.186 \\
\hline & Orosomucoid & 2.61 & {$[0.80-8.45]$} & 0.111 \\
\hline & Log NT-ProBNP & 1.71 & {$[1.14-2.55]$} & 0.009 \\
\hline & Length of HF & 1 & {$[1-1]$} & 0.92 \\
\hline \multicolumn{5}{|c|}{ CV death + HF Hospitalization } \\
\hline & Sarcopenia & 1.39 & {$[0.86-2.26]$} & 0.183 \\
\hline & Dyslipidemia & 1.47 & {$[0.95-2.28]$} & 0.086 \\
\hline & Dilated Cardiomyopathy & 0.34 & {$[0.12-0.93]$} & 0.035 \\
\hline & Log NT-ProBNP & 1.23 & [1.01-1.49] & 0.038 \\
\hline \multicolumn{5}{|c|}{ HF Hospitalization } \\
\hline & Sarcopenia & 1.41 & {$[0.86-2.32]$} & 0.175 \\
\hline & Dyslipidemia & 0.25 & {$[0.08-0.78]$} & 0.018 \\
\hline & Dilated Cardiomyopathy & 1.21 & {$[0.99-1.48]$} & 0.067 \\
\hline
\end{tabular}

$\mathrm{ACEi}=$ Angiotensin Converting Enzyme inhibitor; $\mathrm{BMI}=$ Body Mass Index; $\mathrm{CKD}=$ Chronic kidney disease; HF duration = Mean duration of evolution of chronic heart failure; GFR $=$ Glomerular Filtration Rate in $\mathrm{mL} / \mathrm{min} / 1 / 73 \mathrm{~m}^{2}$, estimated by creatinine clearance via MDRD (Modification of the Diet in Renal Disease); HR= Hazard ratio; $\mathrm{LVEF}=$ left ventricular ejection fraction; NT-pro-BNP $=\mathrm{N}$-Terminal prohormone of Brain Natriuretic Peptide; $\mathrm{CI}=$ Confidence Interval.

Bold describes the statistical significance, $\mathrm{p}<0.05$.

database $[19,20]$ despite the fact that the population in the present study was older, sicker and more frail than the average HFrEF patient. The high prevalence of sarcopenia may reflect the vulnerable status of ADHF patients, but it needs to be emphasized that different reports on prevalence not only address different populations but also often use different definitions of the condition. Masanés et al. have shown that the prevalence varies considerably depending on the cut-off points used [21].

Muscle strength is considered the most reliable measure of muscle function at present and is used as the principal determinant of sarcopenia in the EWGSOP2 recommendations [22]. This is not the case with all studies, a number of which based the diagnosis primarily on muscle mass loss [15]. The SICA-HF study reported a prevalence of $19.5 \%$ of muscle wasting obtained by DEXA among patients with stable HF [15] but ADHF were not included. Comparing with our study, the population was younger $(66.9 \pm 10.4$ years), with a greater proportion of patients with $\mathrm{HFrEF}(69 \%)$ but LVEF was comparable to values in SICA-HF study. We followed the recent recommendations and also added physical performance quantified by the 4MGS test and muscle strength measured by palmar grip strength test. The grip strength test is recommended by the EWGOSP as simple and inexpensive.

When including the caveats above, our prevalence rates are not off the chart compared with other surveys. A recent Italian multicenter study using the same evaluation criteria as in our survey, but with lower threshold values for BIA $\left(8.87 \mathrm{~kg} / \mathrm{m}^{2}\right.$ for men and $6.42 \mathrm{~kg} /$ $\mathrm{m}^{2}$ for women) found a sarcopenia prevalence of $45 \%$ in a subgroup of HF patients hospitalized in an acute setting [23]. If we apply the same BIA threshold values, the prevalence in our population would decrease to $41 \%$, a comparable number. The SICA-HF study reported $19.5 \%$ prevalence of muscle wasting obtained by DEXA among patients with stable HF but without evaluating the functional aspect [15]. Compared with our cohort the population was younger and not hospitalized. As in our cohort, SICA-HF patients with muscle wasting were older and with lower functional abilities. Another small study in muscle wasting assessed by DEXA in young (mean age 37.3 years) patients with non-ischemic dilated cardiomyopathy and severe left ventricular dysfunction found a sarcopenia prevalence of 47.3\% [24]. Finally, Tsuchida et al. [25] recently described a similar rate of sarcopenia as ours $(52.6 \%)$ in a small study of 38 ADHF patients $(60.5 \%$ with LVEF $<40 \%$ ). However, the authors based the diagnosis of

Table 2B

Multivariate analysis of sarcopenia and different endpoints (repeated events).

\begin{tabular}{|c|c|c|c|c|}
\hline Endpoint & Variable & HR & {$[95 \% \mathrm{CI}]$} & p-value \\
\hline \multicolumn{5}{|c|}{ Non-cardiovascular Hospitalization } \\
\hline & Sarcopenia & 1.27 & {$[0.86-1.88]$} & 0.23 \\
\hline & Dyslipidemia & 1.38 & {$[0.96-1.97]$} & 0.083 \\
\hline & Vascular arteriopathy & 2.02 & {$[1.31-3.12]$} & 0.002 \\
\hline & HF length & 1.0018 & {$[1.0001-1.0034]$} & 0.034 \\
\hline & Betablockers & 1.72 & {$[1.13-2.62]$} & 0.011 \\
\hline & History of Cardiac rehabilitation & 0.53 & {$[0.3-0.92]$} & 0.023 \\
\hline \multicolumn{5}{|c|}{ All cause hospitalization } \\
\hline & Sarcopenia & 1.14 & {$[0.91-1.43]$} & 0.253 \\
\hline & Vascular diseases & 1.41 & {$[1.10-1.80]$} & 0.006 \\
\hline & Dilated cardiomyopathy & 0.55 & {$[0.31-0.99]$} & 0.046 \\
\hline & Betablocker & 1.60 & {$[1.23-2.09]$} & 0.001 \\
\hline & Log NT-ProBNP & 1.12 & {$[1.02-1.22]$} & 0.013 \\
\hline & Recent loss of weight & 1.31 & {$[1.01-1.70]$} & 0.045 \\
\hline \multicolumn{5}{|c|}{ CV Hospitalization } \\
\hline & Sarcopenia & 0.64 & {$[0.39-1.06]$} & 0.08 \\
\hline & Sex & 1.77 & {$[1.07-2.94]$} & 0.026 \\
\hline & Familial history of CV disease & 1.97 & {$[1.16-3.32]$} & 0.011 \\
\hline \multicolumn{5}{|c|}{ HF Hospitalization } \\
\hline & Sarcopenia & 1.26 & {$[0.86-1.84]$} & 0.236 \\
\hline & Betablockers & 1.58 & {$[1.03-2.43]$} & 0.037 \\
\hline & Dilated Cardiomyopathy & 0.36 & {$[0.14-0.94]$} & 0.038 \\
\hline & Log NT-ProBNP & 1.27 & {$[1.07-1.50]$} & 0.006 \\
\hline
\end{tabular}

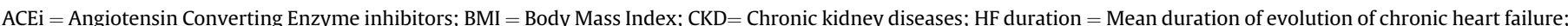

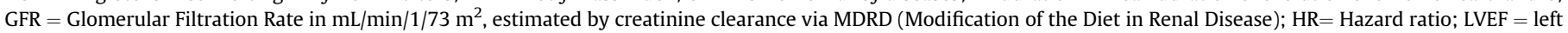
ventricular ejection fraction; NT-pro-BNP $=\mathrm{N}$-Terminal prohormone of Brain Natriuretic Peptide; $\mathrm{CI}=\mathrm{Confidence} \mathrm{Interval}$. 


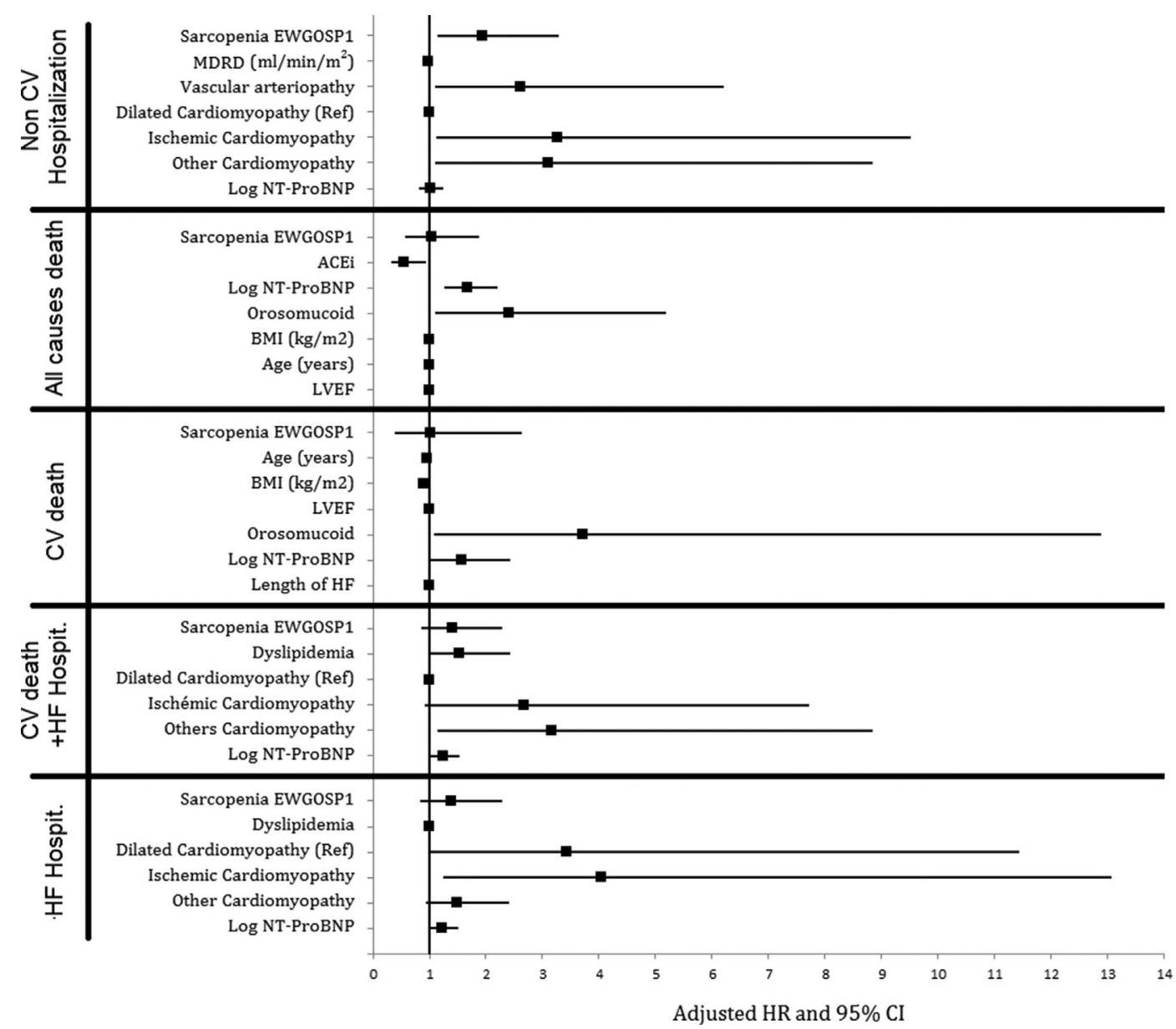

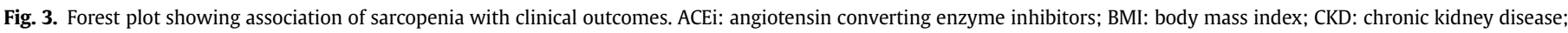

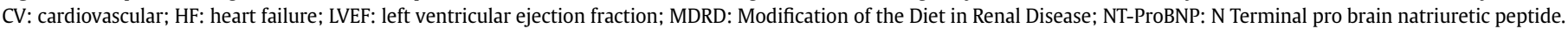

sarcopenia only on muscle mass evaluation (DXA). Moreover, no follow-up data were reported and the time of sarcopenia evaluation after decongestion was unclear. In regard to precipitating factors of HF hospitalization in our cohort, we did not observe any difference between both groups (sarcopenic vs. non-sarcopenic). As also described in other studies we observed classical factors (i.e. evolution of the cardiopathy, poor compliance, anemia or atrial fibrillation) with no difference according to age ( $<70 \mathrm{vs.} \geq 70 \mathrm{yrs}$ ) probably due to the relatively small sample size [26].

To our knowledge, our study is the first to evaluate the impact of sarcopenia on morbidity and mortality in acutely hospitalized HF patients. The increased risk of adverse outcomes in our sarcopenic population was limited to non- $\mathrm{CH}$ hospitalization, although we observed non-significant trends on other endpoints. PINI score and grip strength were significantly worse in the sarcopenic group. High PINI score has been found to be predictive of mortality and chronic institutionalization in elderly patients, although we did not find this within the limited follow-up of our study [27]. Grip strength is a validated risk-stratifying method for all-cause death, CV death, and CV disease [28].

The high prevalence of sarcopenia in ADHF patients should alert clinicians to the need to improve the prognosis of affected patients since some data seemed to demonstrate that muscle mass and muscular strength were protective in HF patients [31,32]. It would be desirable with a prospective, randomized study to evaluate the potential benefit to patients of current practice vs an active strategy (protein-enriched diet + physical exercise) during hospitalization and the first weeks in rehab center or at home.

\subsection{Study limitations}

Limitations to the present study include the absence of a control group and the relatively limited size of our cohort. Although modest, ours is the largest cohort with the longest follow-up presented to date and the prevalence data were compared with an independently surveyed cohort of patients ten years older. Still, the limited sample size may have influenced the outcome results and the robustness of any conclusions. Furthermore, we cannot exclude an underestimation of the true prevalence of sarcopenia in such patients, since patients unable to complete 4MGS and grip tests (i.e. bedridden patients and patients unabled to remain upright for more than few seconds) were not included. As patients were included following hospitalization for HF exacerbation, reduced patient activity during hospitalization may increase the nominal prevalence of sarcopenia. However, this potential confounder may be an additional argument for more stringent evaluation of sarcopenia in hospitalized HF patients. While care was taken in carrying out the tests, in particular impedance analysis, after complete clinical regression of the congestive signs, a possible measurement bias cannot be excluded. Furthermore, BIA is a reproducible, easy to use technique and have been studied for more than 10 years [33]. Furthermore BIA results have been found to correlate well with MRI 
predictions [34]. Lastly, the study was carried out and finalized prior to the publication of the new sarcopenia diagnosis algorithm by the EWGSOP2 group [22]. Thus, the initial SARC-F test, which is mandatory for the EWGSOP2 definition could not be performed in our population. However, if this algorithm had been used in the present population, the rate of sarcopenic patients would remain high (41.4\%). There were no important differences between the populations of sarcopenic patients according to EWGSOP1 vs. EWGSOP2 regarding clinical, biological, or medication characteristics. However, sarcopenic patients defined according to EWGSOP1 seemed to be sicker (i.e. more patients aged $>80 \mathrm{yrs}$, ischemic, with LEVF $<40 \%$, atrial fibrillation, inflammatory diseases, GFR $<60 \mathrm{ml} /$ $\min / 1.73 \mathrm{~m}^{2}$ ) and less well treated (less ACEi) due to the evolution of the definitions. This may explain why sarcopenia was not associated anymore with non-CV hospitalizations in the multivariate analysis (supplementary data). As demonstrated by Liguori et al. the MNA score is linearly related to muscle mass implying that malnutrition and sarcopenia often coexist, and both clinical conditions are associated with negative health outcomes [35]. This is the reason why sarcopenia as assessed by muscle mass loss is included as a phenotypic criterion in the new GLIM criteria for the screening and diagnosis of malnutrition in adults [36]. GLIM recommends the combination of at least one phenotypic criterion and one etiologic criterion. Including muscle mass in the phenotypic criteria will lower the possibility of missing malnourished patients. Hence, using the new criteria, even if only $13.6 \%$ of patients had a recent loss of weight and even if biological markers were in normal range, we may have underestimated malnutrition in our population. This observation strenghten the need to implement MNA criteria including muscle mass in order to better diagnose malnutrition in people where it is difficult to document weight loss or when BMI is considered normal or high, as in HF patients.

\section{Conclusion}

The study identifies a high prevalence of sarcopenia using the EWGSOP definition in patients with acute decompensated HF with an associated higher risk for non-CV hospitalizations over midterm follow-up (trends for HF hospitalization, CV death and HF hospitalization). This high prevalence warrants conducting additional studies in terms of screening and management, in order to improve the long term prognosis of sarcopenic patients with HF.

\section{Statement for autorship}

RE, YB, AM, MB, PLT, MCDB, RR, FJ, GS, BP, PM, PR, GC participated in the design of the study. All authors materially participated in preparation of the article. All authors have approved the final manuscript.

\section{Funding sources}

This work was supported by Clermont-Ferrand University Hospital.

\section{Conflict of interest}

None.

\section{Acknowledgments}

We thank Mrs Bellanger, Chazot, Cubizolles, Lamallem and Thalamy for their work during the different steps of the present study (administrative, kick off, monitoring, ...) and Dr Plaquevant and Pailleret for recruitment, inclusions and collect data.

\section{Appendix A. Supplementary data}

Supplementary data to this article can be found online at https://doi.org/10.1016/j.clnu.2020.12.033.

\section{References}

[1] Morley JE, Anker SD, von Haehling S. Prevalence, incidence, and clinical impact of sarcopenia: facts, numbers, and epidemiology-update 2014. J Cachexia Sarcopenia Muscle 2014;5:253-9. https://doi.org/10.1007/s13539-014-0161-y.

[2] Springer J, Springer J-I, Anker SD. Muscle wasting and sarcopenia in heart failure and beyond: update 2017. ESC Heart Fail 2017;4:492-8. https:// doi.org/10.1002/ehf2.12237.

[3] Stewart S, MacIntyre K, Hole DJ, Capewell S, McMurray JJ. More "malignant" than cancer? Five-year survival following a first admission for heart failure. Eur J Heart Fail 2001;3:315-22.

[4] Carbone S, Billingsley HE, Rodriguez-Miguelez P, Kirkman DL, Garten R, Franco RL, et al. Lean mass abnormalities in heart failure: the role of sarcopenia, sarcopenic obesity, and cachexia. Curr Probl Cardiol 2019:100417. https://doi.org/10.1016/j.cpcardiol.2019.03.006.

[5] Mosterd A, Hoes AW. Clinical epidemiology of heart failure. Heart Br Card Soc 2007;93:1137-46. https://doi.org/10.1136/hrt.2003.025270.

[6] Mancini DM, Walter G, Reichek N, Lenkinski R, McCully KK, Mullen JL, et al. Contribution of skeletal muscle atrophy to exercise intolerance and altered muscle metabolism in heart failure. Circulation 1992;85:1364-73. https:// doi.org/10.1161/01.cir.85.4.1364.

[7] Piepoli MF, Crisafulli A. Pathophysiology of human heart failure: importance of skeletal muscle myopathy and reflexes. Exp Physiol 2014;99:609-15. https://doi.org/10.1113/expphysiol.2013.074310.

[8] Emami A, Saitoh M, Valentova M, Sandek A, Evertz R, Ebner N, et al. Comparison of sarcopenia and cachexia in men with chronic heart failure: results from the Studies Investigating Co-morbidities Aggravating Heart Failure (SICA-HF). Eur J Heart Fail 2018;20:1580-7. https://doi.org/10.1002/ejhf.1304.

[9] Bekfani T, Pellicori P, Morris DA, Ebner N, Valentova M, Steinbeck L, et al. Sarcopenia in patients with heart failure with preserved ejection fraction: impact on muscle strength, exercise capacity and quality of life. Int J Cardiol 2016;222:41-6. https://doi.org/10.1016/j.ijcard.2016.07.135.

[10] Cruz-Jentoft AJ, Baeyens JP, Bauer JM, Boirie Y, Cederholm T, Landi F, et al. Sarcopenia: European consensus on definition and diagnosis: report of the European working group on sarcopenia in older people. Age Ageing 2010;39: 412-23. https://doi.org/10.1093/ageing/afq034.

[11] Janssen I, Heymsfield SB, Ross R. Low relative skeletal muscle mass (sarcopenia) in older persons is associated with functional impairment and physical disability. J Am Geriatr Soc 2002;50:889-96. https://doi.org/10.1046/j.15325415.2002.50216.x.

[12] Chabin X, Taghli-Lamallem O, Mulliez A, Bordachar P, Jean F, Futier E, et al. Bioimpedance analysis is safe in patients with implanted cardiac electronic devices. Clin Nutr Edinb Scotl 2019;38:806-11. https://doi.org/10.1016/ j.clnu.2018.02.029.

[13] Rothman KJ. No adjustments are needed for multiple comparisons. Epidemiol Camb Mass 1990;1:43-6.

[14] Feise RJ. Do multiple outcome measures require p-value adjustment? BMC Med Res Methodol 2002;2:8. https://doi.org/10.1186/1471-2288-2-8.

[15] Fülster S, Tacke M, Sandek A, Ebner N, Tschöpe C, Doehner W, et al. Muscle wasting in patients with chronic heart failure: results from the studies investigating co-morbidities aggravating heart failure (SICA-HF). Eur Heart J 2013;34:512-9. https://doi.org/10.1093/eurheartj/ehs381.

[17] Doehner W, Turhan G, Leyva F, Rauchhaus M, Sandek A, Jankowska EA, et al. Skeletal muscle weakness is related to insulin resistance in patients with chronic heart failure. ESC Heart Fail 2015;2:85-9. https://doi.org/10.1002/ ehf2.12035.

[18] Iwakami N, Nagai T, Furukawa TA, Sugano Y, Honda S, Okada A, et al. Prognostic value of malnutrition assessed by Controlling Nutritional Status score for long-term mortality in patients with acute heart failure. Int J Cardiol 2017;230:529-36. https://doi.org/10.1016/j.ijcard.2016.12.064.

[19] Logeart D, Isnard R, Resche-Rigon M, Seronde M-F, de Groote P, Jondeau G, et al. Current aspects of the spectrum of acute heart failure syndromes in a real-life setting: the OFICA study. Eur J Heart Fail 2013;15:465-76. https:// doi.org/10.1093/eurjhf/hfs189.

[20] Massoullié G, Chouki C, Mulliez A, Rossignol P, Ploux S, Pereira B, et al. Effect of optimization of medical treatment on long-term survival of patients with heart failure after implantable cardioverter defibrillator and cardiac resynchronization device implantation (from the French national EGB database). Am J Cardiol 2018;121:725-30. https://doi.org/10.1016/j.amjcard.2017.12.013.

[21] Masanés F, Rojano I Luque X, Salvà A, Serra-Rexach JA, Artaza I, Formiga F, et al. Cut-off points for muscle mass - not grip strength or gait speed determine variations in sarcopenia prevalence. J Nutr Health Aging 2017;21: 825-9. https://doi.org/10.1007/s12603-016-0844-5.

[22] Cruz-Jentoft AJ, Bahat G, Bauer J, Boirie Y, Bruyère O, Cederholm T, et al. Sarcopenia: revised European consensus on definition and diagnosis. Age Ageing 2019;48:16-31. https://doi.org/10.1093/ageing/afy169.

[23] Bianchi L, Abete P, Bellelli G, Bo M, Cherubini A, Corica F, et al. Prevalence and clinical correlates of sarcopenia, identified according to the EWGSOP 
definition and diagnostic algorithm, in hospitalized older people: the GLISTEN study. J Gerontol A Biol Sci Med Sci 2017;72:1575-81. https://doi.org/ $10.1093 /$ gerona/glw343.

[24] Hajahmadi M, Shemshadi S, Khalilipur E, Amin A, Taghavi S, Maleki M, et al. Muscle wasting in young patients with dilated cardiomyopathy. J Cachexia Sarcopenia Muscle 2017;8:542-8. https://doi.org/10.1002/jcsm.12193.

[25] Tsuchida K, Fujihara Y, Hiroki J, Hakamata T, Sakai R, Nishida K, et al. Significance of sarcopenia evaluation in acute decompensated heart failure. Int Heart J 2018:59:143-8. https://doi.org/10.1536/ihj.17-057.

[26] Testa G, Della-Morte D, Cacciatore F, Gargiulo G, D'Ambrosio D, Galizia G, et al. Precipitating factors in younger and older adults with decompensated chronic heart failure: are they different? J Am Geriatr Soc 2013;61:1827-8. https:// doi.org/10.1111/jgs.12475.

[27] Bonnefoy M, Ayzac L, Ingenbleek Y, Kostka T, Boisson RC, Bienvenu J. Usefulness of the prognostic inflammatory and nutritional index (PINI) in hospitalized elderly patients. Int J Vitam Nutr Res Int Z Vitam- Ernahrungsforschung J Int Vitaminol Nutr 1998;68:189-95.

[28] Leong DP, Teo KK, Rangarajan S, Lopez-Jaramillo P, Avezum A, Orlandini A, et al. Prognostic value of grip strength: findings from the Prospective Urban Rural Epidemiology (PURE) study. Lancet Lond Engl 2015;386:266-73. https://doi.org/10.1016/S0140-6736(14)62000-6.
[31] Lavie CJ, Forman DE, Arena R. Bulking up skeletal muscle to improve heart failure prognosis. JACC Heart Fail 2016;4:274-6. https://doi.org/10.1016/ j.jchf.2015.12.005.

[32] Artero EG, Lee D, Lavie CJ, España-Romero V, Sui X, Church TS, et al. Effects of muscular strength on cardiovascular risk factors and prognosis. J Cardiopulm Rehabil Prev 2012;32:351-8. https://doi.org/10.1097/HCR.0b013e3182642688.

[33] Bioelectrical impedance analysis in body composition measurement: national institutes of health technology assessment conference statement. Am J Clin Nutr 1996;64:524S-32S. https://doi.org/10.1093/ajcn/ 64.3.524S

[34] Janssen I, Heymsfield SB, Baumgartner RN, Ross R. Estimation of skeletal muscle mass by bioelectrical impedance analysis. J Appl Physiol Bethesda Md 1985 2000;89:465-71. https://doi.org/10.1152/jappl.2000.89.2.465.

[35] Liguori I, Curcio F, Russo G, Cellurale M, Aran L, Bulli G, et al. Risk of malnutrition evaluated by mini nutritional assessment and sarcopenia in noninstitutionalized elderly people. Nutr Clin Pract Off Publ Am Soc Parenter Enter Nutr 2018;33:879-86. https://doi.org/10.1002/ncp.10022.

[36] Cederholm T, Jensen GL, Correia MITD, Gonzalez MC, Fukushima R, Higashiguchi $\mathrm{T}$, et al. GLIM criteria for the diagnosis of malnutrition - a consensus report from the global clinical nutrition community. Clin Nutr Edinb Scotl 2019;38:1-9. https://doi.org/10.1016/j.clnu.2018.08.002. 